\title{
Impact of a 2-yr anti-TNF treatment on the quality of life in JIA patients: a parent's/patient's view
}

\author{
K Diafa, P Pratsidou-Gertsi, , M Trachana, G Pardalos, F Kanakoudi-Tsakalidou \\ From 18th Pediatric Rheumatology European Society (PReS) Congress \\ Bruges, Belgium. 14-18 September 2011
}

\section{Background}

The use of biologic factors in the management of Juvenile Idiopathic Arthritis (JIA) has changed dramatically the course and outcome of the disease. They control the disease symptoms and hinder the joint damage which may provoke major functional limitations, thus affecting the patients' Health Related Quality of Life (HRQoL).

\section{Aim}

To evaluate changes in the HRQoL variables in patients with JIA, under anti-TNF treatment.

\section{Methods}

49 patients with refractory to conventional therapy JIA, aged 2-18 years, were studied. They were receiving either Etanercept or Adalimumab for the first time or they were switchers from one anti-TNF to the other one (10/49). All patients were clinically and laboratory assessed pre-treatment and thereafter every 6 months, until the completion of 2 years. At the same timepoints, the following variables were collected: the Childhood Health Assessment Questionnaire (CHAQ) Disability Index (DI), the patient's/parent's global assessment of pain and wellbeing (P/PVAS) and the physician's global assessment (MDVAS) through the visual analogue scale (VAS).

\section{Results}

During anti-TNF treatment, all the above mentioned core set variables P/PVAS showed a significant

\footnotetext{
* Correspondence: jennypg@auth.gr

Pediatric Immunology and Rheumatology Referral Center, 1st Department of Pediatrics, Aristotle University, Ippokration General Hospital, Thessaloniki, Greece
}

improvement $(\mathrm{p}<0.05)$. Similarly, the improvement of MDVAS was positively correlated with the improvement of CHAQ DI (rsq=0.43), of VAS pain ( $r s q=0.66)$ and of VAS wellbeing ( $\mathrm{rsq}=0.64)$. No correlation between VAS wellbeing and JIA duration was found. Pain was the only independent factor related with a poor score of wellbeing.

\section{Conclusion}

This study shows that all variables associated with HRQoL in patients with JIA can be substantially improved after 2 years of anti-TNF treatment.

Published: 14 September 2011

doi:10.1186/1546-0096-9-S1-P125

Cite this article as: Diafa et al:: Impact of a 2-yr anti-TNF treatment on the quality of life in JIA patients: a parent's/patient's view. Pediatric Rheumatology 2011 9(Suppl 1):P125.

Submit your next manuscript to BioMed Central and take full advantage of:

- Convenient online submission

- Thorough peer review

- No space constraints or color figure charges

- Immediate publication on acceptance

- Inclusion in PubMed, CAS, Scopus and Google Scholar

- Research which is freely available for redistribution 